\title{
Physiology of Basal Ganglia Disorders: An Overview
}

\author{
Mark Hallett
}

\begin{abstract}
The pathophysiology of the movement disorders arising from basal ganglia disorders has been uncertain, in part because of a lack of a good theory of how the basal ganglia contribute to normal voluntary movement. An hypothesis for basal ganglia function is proposed here based on recent advances in anatomy and physiology. Briefly, the model proposes that the purpose of the basal ganglia circuits is to select and inhibit specific motor synergies to carry out a desired action. The direct pathway is to select and the indirect pathway is to inhibit these synergies. The clinical and physiological features of Parkinson's disease, L-DOPA dyskinesias, Huntington's disease, dystonia and tic are reviewed. An explanation of these features is put forward based upon the model.
\end{abstract}

RÉSUMÉ: La physiologie des affections du noyau lenticulaire, du noyau caudé, de l'avant-mur et du noyau amygdalien. La pathophysiologie des désordres du mouvement résultant d'affections du noyau lenticulaire, du noyau caudé, de l'avant-mur et du noyau amygdalien est demeurée incertaine, en partie parce qu'il n'existe pas de bonne théorie expliquant le rôle de ces structures anatomiques dans le contrôle du mouvement volontaire normal. Nous proposons ici une hypothèse sur leur fonction basée sur des progrès récents en anatomie et en physiologie. En résumé, le modèle propose que leurs circuits ont pour fonction de sélectionner et d'inhiber des synergies motrices spécifiques pour exécuter l'action désirée. La voie directe est de sélectionner et la voie indirecte est d'inhiber ces synergies. Nous revoyons les manifestations cliniques et physiologiques de la maladie de Parkinson, des dyskinésies dues à la L-DOPA, de la maladie de Huntington, de la dystonie et des tics. Nous proposons une explication de ces manifestations basée sur le modèle exposé.

Can. J. Neurol. Sci. 1993; 20:177-183

Movement disorder is becoming more popular these days as a subspeciality interest in Neurology. The clinical problems are common, often visually dramatic, and a number of good therapies are available. On the other hand, much remains unknown, and there are fertile fields for research in anatomy, physiology and pharmacology. Many movement disorders have their origin in basal ganglia dysfunction, which focuses interest on this primitive structure, deep within the brain. Understanding the genesis of these movement disorders requires understanding of the role of the basal ganglia in movement, but this has been "mysterious." The basal ganglia disorders have been divided into the hyperkinetic movement disorders and the akinetic-rigid syndromes. The first, including chorea, dyskinesias and dystonia, are characterized by the prominent feature of involuntary, undesired movements. The second, including Parkinson's disease, are characterized by the prominent feature of difficulty in generating voluntary movement. Voluntary and involuntary movements may share similar pathways, and the major difference between the two may just be the presence of volition. Volition, at the present time, is a philosophical rather than a neurophysiological concept and is not understood. In particular, it has not been settled whether volition is a process that actually initiates voluntary movement or is a conscious perception produced by the brain during the normal course of movement production. In the latter view, a movement that is "voluntarily" produced is the product of various forces, both intrinsic and extrinsic, acting on the motor system.

I will first review some pertinent features of the principal movement disorders. Then I will review what is known about the anatomy and physiology of the basal ganglia. Lastly, I will propose a scheme to explain how the movement disorders are produced.

\section{Parkinson's Disease}

Parkinson's disease is the prototypical akinetic-rigid syndrome, characterized by slowness of movement and increased tone. The slowness of movement can be divided into failure to move or slowness to initiate movement, which might be called akinesia, and slowness of movement itself, which might be called bradykinesia. In the experimental setting, akinesia is measured by reaction time and bradykinesia is measured by movement time. Patients are also characterized by loss of associated movements.

Increased tone in Parkinson's disease is called rigidity. Its physiology has been studied extensively, and one highly characteristic

From the Human Motor Control Section, Medical Neurology Branch, National Institute of Neurological Disorders and Stroke, National Institutes of Health, Bethesda, Maryland

Received January 18, 1992. Accepted March 31, 1993

Based on the 12th J.L. Silversides Lecture, University of Toronto, May 21, 1992

Reprint requests to: Mark Hallett, M.D., Clinical Director, NINDS, National Institutes of Health, Building 10, Room 5N226, Bethesda, Maryland 20892, USA 
feature is enhancement of long-latency reflexes, such as the long-latency stretch reflex. The experimental way to assess for an increased response to stretch is to give controlled stretches to a muscle and measure the response in terms of force or EMG. Although there is some controversy about it, several studies show that the magnitude of the increase correlates with the clinical impression of increased tone. ${ }^{2}$ Other studies of reflexes in Parkinson's disease have shown a reduction in inhibition of interneuronal circuits; for example, there is enhanced recovery in the blink reflex recovery cycle.

Patients with Parkinson's disease may also have prominent tremors. The most classic is a tremor-at-rest. The presence and degree of severity of tremor seem to be independent of the movement slowness, which clearly is the most significant functional problem for these patients.

Studies with positron emission tomography show a reduced activation of the supplementary motor area (SMA) with voluntary movement and normalization of the activation with apomorphine, a dopaminergic agent that improves the patients clinically. ${ }^{3.4}$ Additionally, Rossini et al..$^{5}$ showed that the N30 of the median nerve somatosensory evoked potential (SEP) was diminished in Parkinson's disease. Other peaks of the SEP were normal, and the N30 had normal latency and topography, but its amplitude was diminished. The origin of the $\mathrm{N} 30$ (as most of the waves of the SEP) is debated, but its topography is anterior and medial to the $\mathrm{N} 20$ that is thought to arise from the hand area of the somatosensory cortex. While far from proven, the N30 could come at least in part from the SMA, which should anatomically lie beneath the topographic peak of the wave. The N30 abnormality may also be reversible with apomorphine. ${ }^{6}$

\section{L-DOPA Dyskinesias}

Patients who receive too much L-DOPA treatment may develop involuntary movements. The movements may affect all parts of the body, and their appearance is similar to chorea. The process is assumed to be an excessive reversal of the dopamine deficiency of Parkinson's disease with excessive facilitation of movement. One curiosity, which has never been satisfactorily explained, is that in late Parkinson's disease treated patients may develop dyskinesias while remaining bradykinetic.

\section{Chorea}

Chorea means "dance" and originally referred to the epidemic dancing manias of the Middle Ages. It was first used medically by Sydenham to describe the involuntary movements in rheumatic disease, and was then used for many other types of movements. Currently, the usage is more restricted, but still refers to a family of similar appearing disorders that differ pathologically and probably physiologically. ${ }^{7}$

The most appropriate adjective to describe chorea is "random". Random muscles throughout the body are affected at random times and make movements of random duration. Movements can be brief, as in myoclonus, or long, as in dystonia. Usually, they are totally without voluntary control, but in some mild cases the movements can be temporarily suppressed. As the movements come on, they are often incorporated into voluntary movements, so that a movement of the arm can become a scratching behind the ear or a movement of the leg when walking can become a dance-like gait. Additionally, voluntary movements cannot be sustained; fluctuation in grip is called "milkmaid's grip" and fluctuation in tongue protrusion is called "darting tongue".

Another abnormality in chorea is that tendon reflexes can be "hung-up". This has the appearance of a prolonged contraction of the muscle whose tendon is stretched. Both in Sydenham's chorea and in Huntington's disease, this abnormality has been demonstrated to be due to a late sensory-provoked choreic movement. ${ }^{7}$ On the other hand, there is a dramatic loss of standard long-latency reflexes in Huntington's disease, including the long-latency stretch reflex. Another reflex abnormality is that blink reflex recovery is delayed, suggesting enhanced inhibition in interneuronal circuits.

Symptomatic treatment is with dopamine-blocking agents, such as haloperidol, or dopamine-depleting agents, such as reserpine. Later in the course of Huntington's disease, bradykinesia and akinesia develop. Thompson et al. ${ }^{8}$ have highlighted the apparent paradox of the coexistence of chorea and bradykinesia.

\section{Hemiballismus}

Hemiballismus is characterized by wild, large-amplitude, irregular limb movements. The responsible lesion is typically in the contralateral subthalamic nucleus, although lesions of the putamen can be responsible. ${ }^{9}$ Hemiballismus in animal models can be produced with subthalamic lesions. The most common clinical circumstance in which hemiballismus can be observed is a stroke where the involuntary movements begin suddenly but only remain violent for a few days before fading into what looks like typical chorea. Hemiballismus is clearly related to chorea, and, like chorea, can be improved with dopamine antagonists.

\section{Dystonia}

Dystonia is a disorder characterized by involuntary movements of sustained muscle contractions, causing prolonged movements or abnormal postures. Movements are often twisting in nature, meaning rotatory about the long axis of a body part. Some patients may also have quick movements, myoclonic dystonia, or tremor, but ordinarily there will have to be some sustained movements for the dystonia to be recognized. Dystonia can be present in any part of the body, and can be classified as focal, segmental, multifocal, generalized, or hemidystonia. Focal dystonia includes affections like blepharospasm, oromandibular dystonia, adductor spasmodic dysphonia, spasmodic torticollis, and writer's cramp. Dystonia can be present during rest, but in general is more likely to appear when the patient is engaged in voluntary activity. Voluntary movements are slow, clumsy, and characterized by overflow (excessive activity in muscles not needed for the task).

With the standard definition of tone as the resistance to passive stretch, the tone in patients with dystonia may be normal or increased. Increased resistance to stretch may come from (1) changes of the biomechanical properties of the muscle or joint, (2) an increased muscular response to stretch, or (3) cocontraction of the muscles acting on the joint. There has been no good study of changes in the biomechanical properties in dystonia, and such changes are not apparent in most patients. On the other hand, such changes would be likely to occur in long-standing disease, where there have been fixed postures.

Studies of stretch reflexes in dystonia have not shown evident abnormalities. Tatton et al. ${ }^{10}$ have suggested that patients with dystonia show long-latency reflexes of long duration. Rothwell 
et al." have not found any abnormality of the amplitude or duration of the stretch reflexes, but have noted that they spread abnormally to other muscles. Because these abnormalities are not marked, we must conclude that increased tone in Parkinson's disease and dystonia are not the same.

Since increased responses to stretch do not seem responsible for the sense of increased tone, cocontraction is left as the best explanation. Cocontraction often seems evident clinically, but the best way to demonstrate it is with electromyography. ${ }^{12-14}$ Cocontraction may well increase during the execution of voluntary movements. Cohen and Hallett ${ }^{15}$ have reported detailed observations on 19 patients with focal dystonias of the hand, including writer's cramp and cramp in piano, guitar, clarinet, and organ players. Five features, identified by physiological investigation, were indicative of impaired motor control. The first was cocontraction, which could be brief. In repetitive alternating movements at a single joint, antagonist muscles typically alternate firing. The dystonia patients might cocontract even with such quick movements. The second feature was prolongation of EMG bursts. Again, this could be subtle. In movements made as quickly as possible, EMG bursts normally last no longer than about $100 \mathrm{~ms}$. The patients might have bursts of 200 or $300 \mathrm{~ms}$ (as well as much-prolonged spasms). The third feature was tremor. The fourth was lack of selectivity in attempts to perform independent finger movements. The fifth feature was occasional failure of willed activity to occur.

Cocontraction can be viewed as a lack of reciprocal inhibition. Interestingly, there is a deficiency of reciprocal inhibition in dystonia. Reciprocal inhibition can be studied in humans by studying the effect of stimulating the radial nerve at various times prior to producing an H-reflex with median nerve stimulation. ${ }^{16.17}$ The radial nerve afferents come from muscles that are antagonist to median nerve muscles. Via various pathways, the radial afferent traffic can inhibit motoneuron pools of median nerve muscles. Normal subjects show three periods of inhibition, reaching a peak at delays of 0,10 , and $75 \mathrm{~ms}$. The first period of inhibition is caused by disynaptic Ia inhibition,the second period of inhibition is explained as a presynaptic inhibition, and, unfortunately, very little is known about the third period of inhibition, but the long latency $(75-200 \mathrm{~ms})$ requires a polysynaptic pathway. The first relative facilitation (at about $2 \mathrm{~ms}$ delay) is a function of lb fiber actions, and indirect evidence indicates that the second facilitation (at about $50 \mathrm{~ms}$ delay) can be a function of cutaneous group II action. Reciprocal inhibition is reduced in patients with dystonia, including those with generalized dystonia, writer's cramp, spasmodic torticollis, and blepharospasm. ${ }^{18.19}$ In the studies of Panizza et al., ${ }^{18,19}$ reduction of inhibition is seen in all three periods, and in similar studies of Rothwell et al. ${ }^{11}$ and Nakashima et al..$^{20}$ the first period was normal, while the second period was reduced (the third period was not studied). It should be noted that reciprocal inhibition can be abnormal even in asymptomatic arms, as in the situation of blepharospasm. In patients with generalized dystonia and spasmodic torticollis, the third period of inhibition was converted from inhibition to potentiation, an inversion of a physiological phenomenon.

Other spinal and brainstem reflexes have been studied, and a common result is that inhibitory processes are reduced. Another example that has been extensively studied is the blink reflex. Abnormalities of blink reflexes were first identified for blepharo- spasm..$^{21}$ Eyelid closure can be spontaneous, but is often aggravated by light or somatosensory stimulation around the eyes, implicating involvement of reflex mechanisms. EMG of orbicularis oculi during a spasm, like in other dystonias, shows an interference pattern of activity similar to a voluntary contraction that typically lasts $200 \mathrm{~ms}$ or more. The blink reflex obtained in the usual manner in patients with dystonia appears normal with normal latencies of the $\mathrm{R} 1$ and $\mathrm{R} 2$ components, but there are abnormalities with the blink reflex recovery cycle. In normal subjects, if a second blink reflex is produced at an interval of less than $3 \mathrm{~s}$ after a first blink reflex, the R2 component of the second blink reflex is reduced in amplitude compared with that of the first blink reflex. The amount of inhibition is proportional to the interval between the two stimuli for production of the blink reflexes. The curve relating the amplitude of the second $\mathrm{R} 2$ to the interval between the stimuli is called the blink reflex recovery cycle. Normal values can be determined, and patients with blepharospasm show less inhibition than normal. Abnormalities of blink reflex recovery have been demonstrated also in generalized dystonia, spasmodic torticollis, and spasmodic dysphonia. ${ }^{22}$ In the last two conditions, abnormalities can be found even without clinical involvement of the eyelids. Similarly, abnormalities are seen with perioral reflexes ${ }^{23}$ and exteroceptive silent periods. ${ }^{24}$

Several observations, therefore, suggest that reduction of spinal cord and brainstem inhibition is an important mechanism in dystonia. Superficially, this would seem to be a good explanation for cocontraction in voluntary movement and increased tone in this disorder. The fundamental disturbance, however, would more likely be an abnormal supraspinal command signal than disordered spinal circuitry.

An important difficulty is that reduction in inhibition is not limited to patients with dystonia. Abnormalities of blink reflex and reciprocal inhibition are also seen in Parkinson's disease. ${ }^{25}$ The similarity of reflex behavior in dystonia and Parkinson's disease parallels many clinical similarities. Both have increased tone and bradykinesia, and, indeed, many times it is difficult to tell the diseases apart. Some patients can present with an apparent mild dystonia and go on to more obvious Parkinson's disease. Perhaps it is not strange that there are physiological similarities. On the other hand, the physiology is clearly not identical. It was pointed out earlier that there are striking differences in longlatency stretch reflex behavior.

Another difference has now been found between Parkinson's disease and dystonia. The N30 studies in our laboratory have demonstrated an enhanced amplitude of the N30 in some patients with dystonia. ${ }^{26}$ The latency and topography appeared normal, but the amplitude was abnormal. This is the opposite of what was found in Parkinson's disease. Additionally, PET studies have shown an increase of activation of the SMA with voluntary movement in patients with dystonia. ${ }^{27}$ This is also opposite to what is seen in Parkinson's disease, and correlates well with the N30 findings.

\section{Tic}

Tics are quick involuntary movements that are repetitive at irregular intervals. The unique feature of tic is that it is not completely involuntary. Most patients describe a psychic tension that builds up inside of them and which can be relieved by the tic movement. Patients "let the tic happen" (or perhaps even 
"make the tic") in order to relieve the tension. In one series, 41 of 60 tic disorder patients stated that all their motor and phonic tics were intentionally produced; 15 others had both voluntary and involuntary components, usually with the former predominating. ${ }^{28}$ The tics can be voluntarily suppressed for some period of time at the expense of letting the psychic tension rise. The movements look like quick voluntary movements both clinically and electromyographically. EMG bursts vary from 50 to $200 \mathrm{~ms}$ in duration and may have the pattern of voluntary ballistic movements.

Tics can be simple or complex movements. Each tic is stereotyped, and patients can have only a single type of tic or multiple tics. Patients can have the multiple tics serially or at the same time. A patient affected by multiple tics simultaneously might look like a patient with multifocal myoclonus or chorea.

Because of the voluntary features of tic, some authorities have thought that tic is a psychiatric disorder, produced entirely by emotional disturbances. There is now good evidence that tics differ from pure voluntary movements. Normal, self-paced voluntary movements are preceded by a long, slow EEG negativity called the bereitschaftspotential; this potential is not seen prior to simple tics, but is seen for similar movements produced voluntarily by the same patients. ${ }^{29}$ Tics may also continue during sleep. ${ }^{30}$

The most common tic disorder is "transient tic of childhood". This is a single type of tic that affects a child for several weeks to as long as a year and then disappears. There is also a "chronic tic" disorder that begins in childhood or adult life. Characteristic of this disorder is a stereotyped tic with a rather constant frequency over the years. A distinctive tic disorder that has been studied extensively is the Gilles de la Tourette syndrome (Tourette syndrome). It is a chronic multiple tic disorder with childhood onset. Features include age of onset between 5 and 10 years, male to female ratio of 3-4 to 1 , often positive family history, waxing and waning tic frequency over months and years, and a high incidence of soft neurological signs, including EEG abnormalities. Vocal tics such as grunting noises are frequent, and a characteristic feature is coprolalia.

Tourette syndrome has been treated most successfully with dopamine blockers, particularly haloperidol. ${ }^{31}$ Stimulant drugs can produce tics or compulsive behaviors. ${ }^{32}$ The anatomical substrate of tic is unknown, but the relation to dopaminergic mechanisms is suggestive of a basal ganglia cause.

There seems to be a close relationship between tic and obsessivecompulsive disorder (OCD) ${ }^{33}$ Many patients show both disorders. Family studies show tic to be inherited as an autosomal dominant trait, with the syndrome sometimes manifesting itself only as OCD. Physiologically, there may be a similarity between tic and an obsession or compulsive behavior. Both the urge to tic and an obsessive thought arise involuntarily, then increase an inner feeling of tension until either the movement is made or the compulsive behavior is carried out.

Another important fact to keep in mind is the increased coexistence of tics and dystonia. Stone and Jankovic have described 9 patients with tics who developed dystonia. ${ }^{34}$ In their clinic, $5 \%$ of patients with Tourette syndrome have dystonia.

\section{Basic Anatomy, Physiology and Pharmacology of the Basal Ganglia}

Figure 1 shows the anatomical pathways involving the basal ganglia. ${ }^{35}$ Influence of the cortex on the putamen is excitatory.
Output from the thalamus to cortex is excitatory, output from the internal division of the globus pallidus (GPi) to thalamus is inhibitory. Two pathways link the putamen and GPi. The "indirect" path, from putamen to the external division of the globus pallidus (GPe) to subthalamic nucleus to $\mathrm{GPi}$, has been recently emphasized because it seems important in regard to understanding the pathophysiology of Parkinson's disease. The "direct" path links the putamen and GPi directly. The output neurons in the indirect pathway utilize GABA and enkephalin, while the output neurons of the direct pathway utilize GABA and substance P. The substantia nigra pars compacta ( $\mathrm{SNpc}$ ) is inhibitory to the neurons of the indirect pathway, but excitatory to the neurons of the direct pathway. Background activity in the putamen is lowfrequency firing, whereas background activity in the GPi is high-frequency firing. A burst of activity in the putamen (e.g. produced by a burst of activity from the cortex), facilitated by the SNpc, would produce a pause in the GPi via the direct pathway. This burst would release the thalamus from tonic inhibition and excite the cortex. ${ }^{36}$ Thus, the direct pathway is a positive feedback circuit. The same burst in the putaminal neurons of the indirect pathway, dampened by the SNpc, would excite the neurons of GPi to even higher levels of activity, depressing the thalamus. Thus, the indirect pathway is a negative feedback circuit. A second output of the GPi is to the pedunculopontine nucleus (PPN).

\section{A Model of Basal Ganglia Function: An Hypothesis}

As I have suggested earlier, the basic idea of the hypothesis is that the purpose of the basal ganglia circuits is to select and inhibit specific motor synergies to carry out a desired action. ${ }^{37}$ The direct path is to select and the indirect path is to inhibit these synergies. The pathway to the thalamus is for specific movements, while the pathway to the PPN is for postural and reflex influences. The circuitry acts to enhance one motor action and inhibit others, similar to the process of surround inhibition in sensory systems. [This notion was one of the possible mechanisms suggested by Alexander and Crutcher. ${ }^{35}$ ] While the influence of the PPN on movement is not well established, I will take the view that the normal net effect of its influence is inhibitory, following the experiments of Kelland and Asdourian. ${ }^{38}$ This makes the influence of the basal ganglia opposite on voluntary movement and spinal reflexes. When voluntary movement is facilitated, reflexes are inhibited and vice versa. Special note should be made of the implication of the model that the influence of the SNpc works to facilitate movement in both the direct and indirect pathways. The model might be viewed as an extension of the one proposed by Penney and Young, who emphasized the influences of disorders of the indirect pathway. ${ }^{39}$

Using the model, deficits can be predicted from specific lesions (Table 1). The overactive indirect pathway increases GPi activity and suppresses thalamic activity, making it difficult to initiate movement. As a result of the influence on the PPN, on the other hand, reflex responsiveness is increased, giving rise to rigidity. The underactive indirect pathway decreases GPi activity, releasing thalamic activity and causing involuntary movement. The overactive direct pathway gives rise to excessive voluntary movement, including overflow of voluntary movement. The underactive direct pathway would make the generation of voluntary movement difficult and slow.

The model makes a distinction between involuntary movements of the choreic type from those of the dystonic/tic type. 


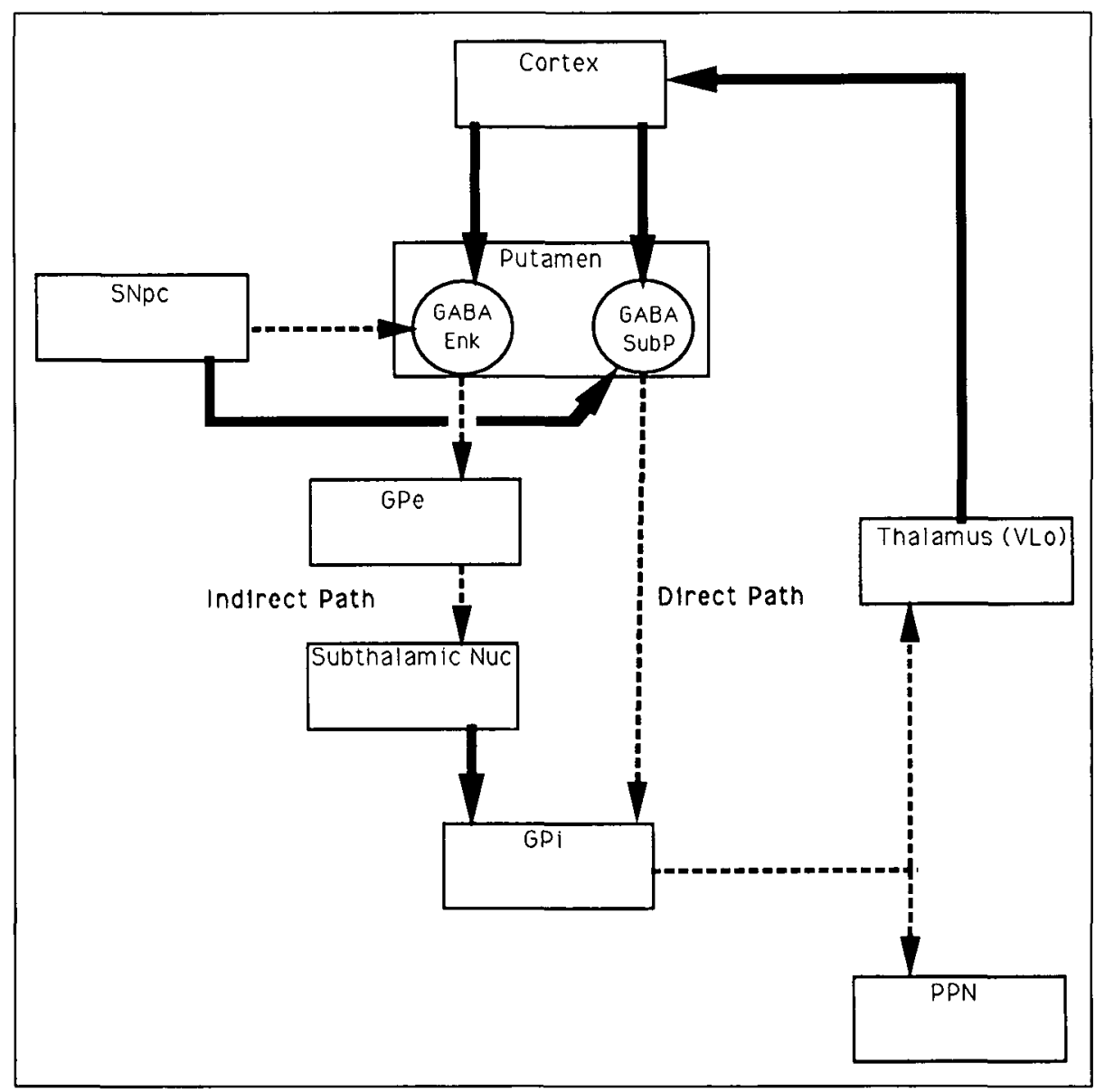

Figure 1-Anatomical pathways involving the basal ganglia. Solid lines indicate excitatory connections and dashed lines indicate inhibitory connections. $S N p c$, substantia nigra pars compacta: Enk, enkephalin; SubP, substance $P$; GPe, external division of the globus pallidus; GPi, internal division of the globus pallidus; PPN, pedunculopontine nucleus; VLo, pars oralis portion of the ventrolateral thalamus. Modified from Alexander and Crutcher: ${ }^{35}$

Table 1. Motor Disturbances Predicted from the Basal Ganglia Model

\begin{tabular}{ll}
\hline \hline Disordered Process & Clinical Result \\
\hline 1. Overactive indirect pathway & Akinesia, rigidity \\
2. Underactive indirect pathway & Chorea, hemiballismus \\
3. Overactive direct pathway & Dystonia, athetosis, or tic \\
4. Underactive direct pathway & Bradykinesia \\
\hline
\end{tabular}

Table 2. Movement Disorders as Explained by the Basal Ganglia Model

\begin{tabular}{lll}
\hline \hline Disorder & Pathophysiology & $\begin{array}{c}\text { Disordered } \\
\text { Process } \\
\text { (from Table 1) }\end{array}$ \\
\hline $\begin{array}{l}\text { Parkinson's } \\
\text { disease }\end{array}$ & $\begin{array}{c}\text { Decreased dopamine } \\
\text { from SNpc } \\
\begin{array}{c}\text { L-DOPA } \\
\text { dyskinesia }\end{array}\end{array}$ & 1 and 4 \\
$\begin{array}{l}\text { Early Huntington's } \\
\text { disease }\end{array}$ & $\begin{array}{l}\text { Decreased exogenous } \\
\text { activity of the GABA-enk } \\
\text { neurons }\end{array}$ & 2 and 3 \\
$\begin{array}{l}\text { Late Huntington's } \\
\text { disease }\end{array}$ & $\begin{array}{l}\text { Decreased putaminal } \\
\text { activity of both types of } \\
\text { GABA neurons }\end{array}$ & 2 and 4 \\
$\begin{array}{l}\text { Hemiballismus } \\
\text { Dystonia }\end{array}$ & $\begin{array}{l}\text { Subthalamic nucleus lesion } \\
\text { Overactivity of the putamen } \\
\text { Tic }\end{array}$ & 2 \\
\hline
\end{tabular}

The former are fully involuntary. The latter are more likely to be produced by an overflow of voluntary movement or a "released" voluntary movement. The model also attempts to distinguish between rigidity, which is a heightened reactivity to stimuli, and overactivity of muscle such as cocontraction, which could come from an overactive direct pathway.

In relation to physiological results discussed for the different disorders, the model must include the idea that the direct pathway influences the SMA, the N30 and long-latency reflexes, while the indirect pathway influences inhibitory reflexes. Exaggerated long-latency reflexes would come from underactivity of the direct pathway. Loss of inhibition of spinal and brainstem reflexes would come from overactivity of the indirect pathway.

\section{An Explanation of the Movement Disorders Based on the Model (Table 2)}

The explanation for Parkinson's disease and L-DOPA dyskinesias is straightforward and clearly consistent with the clinical data and animal models. The pathophysiology of Parkinson's disease is degeneration of the SNpc and diminution of its dopaminergic influence on the putamen. This would lead to loss of facilitation of movement by both pathways. Consistent with the model, in the MPTP monkey there is increased activity in the subthalamic nucleus and $\mathrm{GPi}^{40.41}$ The model can explain how the patient with Parkinson's disease treated with L-DOPA can be bradykinetic and exhibit dyskinesias at the same time. This would occur with excessive activation of the indirect path, but insufficient activation of the direct path. 
The explanation for Huntington's disease is also consistent with the current understanding of the neuronal degenerations in that disorder. The neuronal system most involved early in the disease is the GABA-enkephalin neuron of the striatum. ${ }^{41}$ This is the neuron of the indirect pathway, and when its influence declines, there should be release of inhibition of the thalamus and resulting involuntary movement. In animal models of chorea, overactivity of the GPe and underactivity of the subthalamic nucleus have been demonstrated. ${ }^{42}$ Symptomatic treatment with dopamine-blocking agents should have the effect of increasing activity in the remaining putaminal neurons of the indirect pathway. Later in the course of Huntington's disease with the clinical development of bradykinesia, there is further degeneration of many neurons in the striatum, including the GABA-substance $P$ neurons. ${ }^{4}$ This would give rise to an underactive direct pathway, similar to what is seen with Parkinson's disease. This is an attractive explanation for the "paradoxical" combination of chorea and bradykinesia in Huntington's disease, as originally suggested by Thompson et al. ${ }^{8}$

The anatomical basis of dystonia is not known, although in many cases of secondary dystonia there are basal ganglia lesions, most often in the putamen. ${ }^{43}$ By the model presented here, the new idea emerges that dystonia could come from overactivity of the putamen. The primary disorder would be overactivity of the direct pathway and a secondary disorder shared with Parkinson's disease would be overactivity of the indirect pathway. This mechanism would explain some of the similarities and differences between Parkinson's disease and dystonia. The slowness and some reflex similarities could be due to overactivity of the indirect pathway. The akinesia and loss of associated movements in Parkinson's disease and the excessive movement in dystonia could be explained by the opposite effects on the direct pathway. This would also explain the differences in the $\mathrm{N} 30$, the PET results relating to activation of the SMA with voluntary movement, and behavior of the long-latency stretch reflex.

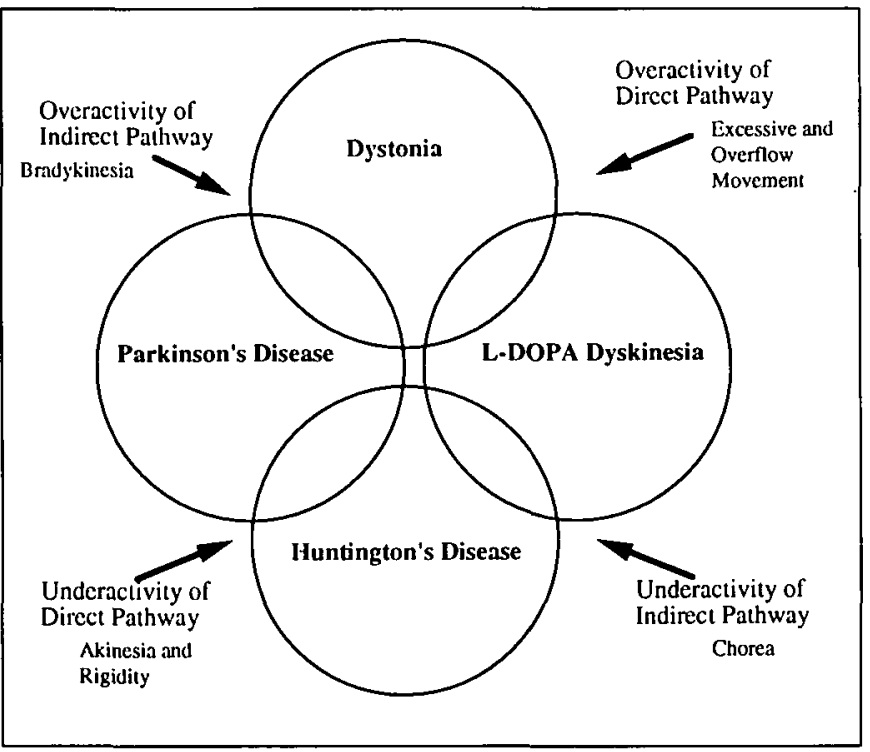

Figure 2 - Venn diagram of different basal ganglia disorders showing separations and overlaps. See text and Table 2 for further explanations.
The pathology of tic is also unknown, and the concept that tic might arise from overactivity of the direct pathway similar to dystonia is a novel explanation. The nature of the overactivity of the direct pathway would have to differ in the two disorders, because voluntary movements in patients with tic do not seem disordered in the same way as those of patients with dystonia. Some sharing of pathophysiology might explain the excessive coexistence of these two disorders.

The similarities and differences between these disorders can be illustrated with a Venn diagram (Figure 2). While the model at present contains a good deal of speculation, it does serve to organize much of the established material and is entirely subject to experimental analysis with current techniques.

\section{REFERENCES}

1. Marsden $C D$. The mysterious motor function of the basal ganglia. Neurology 1982; 32: 514-539.

2. Hallett M. Long-latency reflexes. I $n$ : Quinn NP, Jenner PG, eds. Disorders of Movement. London: Academic Press, 1989: 529. 541.

3. Playford ED, Jenkins IH, Passingham RE, Nutt J, Frackowiak RSJ, et al. Impaired mesial frontal and putamen activation in Parkinson's disease: a positron emission tomography study. Ann Neurol 1992; 32: 151-161.

4. Jenkins IH, Fernandez W, Playford ED, Lees AJ, Frackowiak RSJ, et al. Impaired activation of the supplementary motor area in Parkinson's disease is reversed when akinesia is treated with apomorphine. Ann Neurol 1992; 32: 749-757.

5. Rossini PM, Babiloni F, Bernardi G, Cecchi L, Johnson PB, et al Abnormalities of short-latency somatosensory evoked potentials in parkinsonian patients. Electroencephalogr Clin Neurophysiol 1989; 74: 277-289.

6. Rossini P, Boccasena P, Passarelli F, Traversa R, Pacifici L, et al Frontal SEP changes in Parkinsonian patients during apomorphine test. Abstracts of IX International Congress of Electromyography and Clinical Neurophysiology, Jerusalem, Israel, June 8-12, 1992: 359.

7. Hallett M, Ravits J. Involuntary movements. In: Asbury AK, McKhann GM, McDonald WI, eds. Diseases of the Nervous System. Clinical Neurobiology. Philadelphia: W.B. Saunders, 1986: 452-460.

8. Thompson PD, Berardelli A, Rothwell JC, Day BL, Dick JP, et al. The coexistence of bradykinesia and chorea in Huntington's disease and its implications for theories of basal ganglia control of movement. Brain 1988; 111: 223-244.

9. Dubinsky RM, Greenberg M, DiChiro G, Baker M, Hallett M. Hemiballismus: study of a case using positron emission tomography with ${ }^{18}$ fluoro-2-deoxyglucose. Mov Disord 1989; 4: 310319.

10. Tatton WG, Bedingham W, Verrier MC, Blair RD. Characteristic alterations in responses to imposed wrist displacements in parkinsonian rigidity and dystonia musculorum deformans. Can J Neurol Sci 1984; 11: 281-287.

11. Rothwell JC, Obeso JA, Day BL, Marsden CD. Pathophysiology of dystonias. Adv Neurol 1983; 39: 851-863.

12. Herz E. Dystonia. Historical review: analysis of dystonic symptoms and physiologic mechanisms involved. Arch Neurol Psychiatry 1944; 51: 305-318.

13. Yanagisawa N, Goto A. Dystonia musculorum deformans, analysis with electromyography. J Neurol Sci 1971; 13:39-65.

14. Hughes M, McLellan DL. Increased co-activation of the upper limb muscles in writer's cramp. J Neurol Neurosurg Psychiatry 1985; 48: 782-787.

15. Cohen G, Hallett M. Hand cramps: clinical features and electromyographic patterns in a focal dystonia. Neurology $1988 ; 38: 1005-1012$.

16. Day BL, Marsden CD, Obeso JA, Rothwell JC. Reciprocal inhibition between the muscles of the human forearm. J Physiol (Lond) 1984; 349: 519-534. 
17. Berardelli A, Day BL, Marsden CD, Rothwell JC. Evidence favoring presynaptic inhibition between antagonist muscle afferents in the human forearm. J Physiol (Lond) 1987; 39: 71-83.

18. Panizza $M$, Hallett $M$, Nilsson J. Reciprocal inhibition in patients with hand cramps. Neurology 1989; 39: 85-89.

19. Panizza M, Lelli S, Nilsson J, Hallett M. H-reflex recovery curve and reciprocal inhibition of $\mathrm{H}$-reflex in different kinds of dystonia. Neurology 1990; 40: 824-828.

20. Nakashima K, Rothwell JC, Day BL, Thompson PD, Shannon K, et al. Reciprocal inhibition in writer's and other occupational cramps and hemiparesis due to stroke. Brain 1989; 112: 681-697.

21. Berardelli A, Rothwell JC, Day BL, Marsden CD. Pathophysiology of blepharospasm and oromandibular dystonia. Brain 1985; 108 : 593-608.

22. Cohen LG, Ludlow CL, Warden M, Estegui M, Agostino R, et al. Blink reflex excitability recovery curves in patients with spasmodic dysphonia. Neurology 1989; 39: 572-577.

23. Topka H, Hallet M. Perioral reflexes in orofacial dyskinesia and spasmodic dysphonia. Muscle Nerve 1992; 15: 1016-1022.

24. Nakashima K, Thompson PD, Rothwell JC, Day BL, Stell R, et al. An exteroceptive reflex in the sternocleidomastoid muscle produced by electrical stimulation of the supraorbital nerve in normal subjects and patients with spasmodic torticollis. Neurology 1989; 39: 1354-1358.

25. Lelli S, Panizza M, Hallett M. Spinal cord inhibitory mechanisms in Parkinson's disease. Neurology 1991; 41: 553-556.

26. Reilly JA, Hallett M, Cohen LG, Tarkka IM, Dang N. The N30 component of somatosensory evoked potentials in patients with dystonia. Electroencephalogr Clin Neurophysiol 1992; 84: 243-247.

27. Playford ED, Passingham RE, Marsden CD, Brooks DJ. Abnormal activation of striatum and dorsolateral prefrontal cortex in dystonia [abstract]. Neurology 1992; 42 (Suppl 3): 377.

28. Lang A. Patient perception of tics and other movement disorders. Neurology 1991; 41: 223-228.

29. Obeso JA, Rothwell JC, Marsden CD. Simple tics in Gilles de la Tourette's syndrome are not prefaced by a normal premovement potential. J Neurol Neurosurg Psychiatry 1981; 44: 735-738.
30. Glaze DG, Frost JD, Jankovic J. Sleep in Gilles de la Tourette's syndrome: disorder of arousal. Neurology 1983; 33: 586-592.

31. Shapiro E, Shapiro AK, Fulop G, Hubbard M, Mandeli J, et al. Controlled study of haloperidol, pimozide and placebo for the treatment of Gilles de la Tourette's syndrome. Arch Gen Psychiatry 1989; 46: 722-730.

32. Borcherding BG, Keysor CS, Rapoport JL, Elia J, Amass J. Motor/vocal tics and compulsive behaviors on stimulant drugs: is there a common vulnerability? Psychiatry Res 1990; 33: 83-94.

33. Singer HS, Walkup JT. Tourette syndrome and other tic disorders. Diagnosis, pathophysiology, and treatment. Medicine (Baltimore) 1991; 70: 15-32.

34. Stone LA, Jankovic J. The coexistence of tics and dystonia. Arch Neurol 1991; 48: 862-865.

35. Alexander GE, Crutcher MD. Functional achitecture of basal ganglia circuits: neural substrates of parallel processing. Trends Neurosci 1990; 13: 266-271.

36. Chevalier G, Deniau JM. Disinhibition as a basic process in the expression of striatal function. Trends Neurosci 1990; 13: 277-280.

37. Hallett M, Khoshbin S. A physiological mechanism of bradykinesia. Brain 1980; 103: 301-314.

38. Kelland MD, Asdourian D. Pedunculopontine tegmental nucleusinduced inhibition of muscle activity in the rat. Behav Brain Res 1989; 34: 213-234.

39. Penney JB Jr, Young AB. Speculations on the functional anatomy of basal ganglia disorders. Annu Rev Neurosci 1983; 6: 73-94.

40. Miller WC, DeLong MR. Parkinsonian symptomatology. An anatomical and physiological analysis. Ann NY Acad Sci 1988; 515: 287-302.

41. DeLong MR. Primate models of movement disorders of basal ganglia origin. Trends Neurosci 1990; 13: 281-285.

42. Mitchell IJ, Jackson A, Sambrook MA, Crossman AR. The role of the subthalamic nucleus in experimental chorea. Brain 1989; 112: 1533-1548.

43. Burton K, Farrell K, Li D, Calne DB. Lesions of the brain and dystonia: CT and magnetic resonance imaging. Neurology 1984; 34 : 962-965. 